\title{
Effectiveness of Magnesium Sulphatein Term Neonate with Perinatal Asphyxia: A Study in Faridpurmedical College Hospital, Faridpur, Bangladesh
}

\author{
Md. Mahmuder Rahman Firoz* \\ Assistant Professor, Dept. of Pediatrics, Faridpur Medical College Hospital, Faridpur, Bangladesh
}

*Corresponding Author: Md. Mahmuder Rahman Firoz, Assistant Professor, Dept. of Pediatrics, Faridpur Medical College Hospital, Faridpur, Bangladesh, E-mail: mahmuder.firoz@gmail.com

\begin{abstract}
Introduction: Perinatal asphyxia (PA) or neonatal hypoxic ischemic encephalalopathy (HIE) is an insult to the foetus due to temporary interruption of oxygen availability to various organs. It is one of the leading causes of neonatal death and major attribute to neuromotar disability.
\end{abstract}

Objective: To determine effectiveness of Magnesium Sulphate infusion in full term neonate suffering from moderate and severe perinatal asphyxia.

Methods: The present study was conducted in the Dept. of Pediatrics, Faridpur Medical College Hospital, Faridpur, Bangladesh from June 2019 to December 2019. The study was approved by the hospital ethics committee beforehand. All full term neonates admitted within 6 hour of birth with moderate or severe perinatal asphyxia were included in study. Full term neonates with perinatal asphyxia were selected and classified according to criteria laid by Sarnat and Sarnat. After recording baseline characteristics they were randomly assigned to receive either 3 doses of magnesium sulfate infusion at $250 \mathrm{mg} / \mathrm{kg} /$ dose 24 hours apart (treatment group) or 3 doses of normal saline infusion at $1 \mathrm{ml} / \mathrm{kg} / \mathrm{dose} 24$ hours apart (placebo group). Neurological assessment was performed at time of admission and at fourteenth day. Distributions of perinatal factors, neonatal baseline characteristics, and mean time for initial infusions were noted in pre designed proforma and analyzed statistically.

Results: Distribution of neonatal baseline characteristics and severity of hypoxic-ischemic encephalopathy were similar in treatment and placebo groups. In our study, postnatal magnesium sulfate infusion was found neuroprotective in moderate encephalopathy, which was reflected by early control of seizures $(p=0.04)$, early appearance of normal cry $(p=0.02)$, early appearance of normal activity $(p=0.02)$, early acceptance of full oral feed by sucking $(p=0.04)$. Postnatal magnesium sulfate infusion was not found neuroprotective in severe encephalopathy $(p=>0.05)$. No significant differences were observed in the cranial sonography and electroencephalography between treated and placebo groups $(p=>0.05)$. No significant differences were observed in blood pressure, heart rate and respiratory rate between both the groups.

Conclusion: Postnatal magnesium sulfate therapy may result in early recovery and favorable neurological outcome in term neonates with moderate encephalopathy.

Keywords: Perinatal Asphyxia, Neonate, Magnesium Sulfate, Encephalopathy.

\section{INTRODUCTION}

Perinatal asphyxia (PA) or neonatal hypoxic ischemic encephalalopathy (HIE) is an insult to the foetus due to temporary interruption of oxygen availability to various organs [1]. It is one of the leading causes of neonatal death and major attribute to neuromotar disability. The incidence of perinatal asphyxia is 1-2 per 1000 live birth in developed countries and upto 5 per 1000 in developing countries [2].In Bangladesh, the national neonatal perinatal database, a pooled data from several studies from different parts of country, reported an incidence of 5\% [3]. It is third major cause of neonatal death, after infections and preterm births, in developing countries [4]. Moderate and severe hypoxic ischemic encephalopathy causes significant morbidity and mortality in the neonatal period [5]. Neurologic abnormality at discharge is a strong predictor of long-term neuro developmental delay [3].It is well known 
that hypoxic-ischemic injury leads to a biphasic pattern of neuronal cell death. Primary neuronal injury, which includes cell swelling and necrosis, occurs during the process of asphyxia and stops with resuscitative measures. Excitotoxicity, inflammation and oxidative stress culminating to cell death occurs during secondary phase of neuronal insult, which continues for hours to days [1]. Glutamate is a major excitatory amino acid within brain. It acts on the N-methyl-D-aspartate (NMDA) receptor, a postsynaptic ion channel in the brain. During asphyxia, high concentrations of glutamate open NMDA channels, allowing excessive calcium influx into the neurons leading to irreversible neuronal injury [1, 6]. Magnesium is a naturally occurring NMDA receptor antagonist that blocks the NMDA ion channelduring resting conditions. This block is voltage dependent and is overcome during axonal depolarization during hypoxic ischemic insult. Increase in extracellular concentration of magnesium is supposed to restore this blockade [1]. This beneficial effect of magnesium sulphate in full term neonates with perinatal asphyxia is still dubious and only few studies revealed beneficial results [7]. In view of conflicting data about its effectiveness and paucity of Bangladeshi studies, we performed a randomized controlled trial to test whether postnatal magnesium sulfate infusion could improve neurologic outcomes in term neonates with perinatal asphyxia.

\section{Methods AND MATERIALS}

The present study was conducted in the Dept. of Pediatrics, Faridpur Medical College Hospital, Faridpur, Bangladesh from June 2019 to December 2019. The study was approved by the hospital ethics committee beforehand. All full term neonates admitted within 6 hour of birth with moderate or severe perinatal asphyxia were included in study. Perinatal asphyxia was defined by American Academy of Pediatrics (AAP) and American College of Obstetrics and Gynecology (ACOG) [1]. Severity of asphyxia was determined as per the guidelines laid by Sarnat and Sarnat [8]. Neonate with severe intrauterine growth retardation, congenital malformation, chromosomal anomalies or age more than 6 hours at admission was excluded from the study. After informed consent from parent or caregiver, eligible infants were assigned randomly, using random number table to either treatment group or placebo group. The treatment group received magnesium sulphate infusion at $250 \mathrm{mg} / \mathrm{kg}$ per dose in $20 \mathrm{ml}$ of $5 \%$ dextrose solution over 1 hour, with 2 additional doses repeated at intervals of 24 hours. The placebo group received 3 doses $(1 \mathrm{ml} / \mathrm{kg} / \mathrm{dose})$ of normal saline solution in $20 \mathrm{ml}$ of 5\% dextrose solution, 24 hours apart. Blood pressure, heart rate, respiratory rate and oxygen saturation were monitored in all neonates in both the treatment and placebo groups during initial 72 hours.

All neonates were nursed on servo-controlled, open-care bed, with skin temperature maintained at 36.5 degree Celsius. Other supportive treatment including oxygen therapy, $10 \%$ dextrose solution, electrolytes, Vasopressors or ventilator support were provided as and when needed. Laboratory assessments including arterial blood gas analysis, complete blood count, $\mathrm{C}$ reactive protein, blood urea, serum creatinine, serum bilirubin, serum electrolyte were estimated. Serum magnesium level was obtained at 0,24 , 48,72 hours of magnesium sulphate infusion. Cranial ultrasonography and Electroencephalography were performed initially within 72 hours after admission and was repeated at day 14. CT scan of head or MRI of brain was done as and when needed. Neurological assessment including control of seizures, appearance of normal activity, and appearance of normal cry and appearance of full oral feed by sucking were noted during hospital stay. Good short term outcome means survival with normal cranial ultrasonography, normal electroencephalography and established oral feed by sucking at day 14 . Neurological assessment was performed by clinician who was blinded to the group assignment of the patients at time of admission and at fourteenth day. The data were recorded on pre-structured proforma and was analyzed statistically using SPSS version 16.0. Continuous variables were analyzed by student's t-test. Categorical variables were analyzed by Fisher's exact probability test. Findings associated with a value of $p<0.05$ were considered significant.

\section{ReSUlts}

A total of 97 neonates with perinatal asphyxia were screened. Out of these 97 neonates, 40 neonates were excluded (inclusion criteria not fulfilled for 32 neonates and parents refused to participate for 15 neonates). Hence 50 neonates fulfilled the inclusion criteria and constituted the study group. Among them 34(68\%) were suffering from moderate and rest from severe perinatal asphyxia. Distributions of perinatal 
Effectiveness of Magnesium Sulphatein Term Neonate with Perinatal Asphyxia: A Study in Faridpurmedical College Hospital, Faridpur, Bangladesh

factors, neonatal baseline characteristics, and mean time for initial infusion were similar in the treated and control group (Table 1). They were further divided into treatment $(n=25)$ and placebo $(n=25)$ group. In neonates treated with Magnesium sulphate, mean serum magnesium level was $2.87 \pm 0.28$ and $2.91 \pm 0.74 \mathrm{mEq} / \mathrm{L}$ in moderate and severe group respectively. In our study, first dose of magnesium sulfate was given at $125.31 \pm 70.79$ minute. The neonates with moderate asphyxia, treatment group showed stastitistically significant improvement in terms of control of seizure $(13.67 \pm 1.67$ vs $17.92 \pm 2.67$; P-0.04), appearance of normal cry (10.8 $\pm 1.15 \mathrm{vs} 12.09 \pm 1.37$; P-0.02), appearance of normal activity $(12.2 \pm 1.01$ vs13.43 \pm 1.63 ; P-
0.02), acceptance of full oral feed by sucking $(13.46 \pm 1.19$ vs $14.72 \pm 1.73$; P-0.04) and mean duration in hospital say $(15.05 \pm 2.09$ vs16.63 \pm 2.16 ; P- 0.03)(Table-2). There was no significant difference in mean arterial pressures between the treatment and placebo groups (44.9 \pm 1.1 vs. $44.8 \pm 1.5$; p-0.36). Among severe group more numbers were recovered in all above mentioned parameters but data did not meet statistical significance. There was no significant difference in improvement in cranial ulrasonography and electroencephalography at 14 day in both the groups. This finding underscores the importance of clinical examination in these patients. No significant difference in motality was noted in both groups.

Table1: Baseline characteristics of study group at admission.

\begin{tabular}{|c|c|c|c|c|}
\hline No & Characteristics & Treated group $\mathrm{N}=25$ & $\begin{array}{c}\text { Placebo group } \\
\mathbf{N}=\mathbf{2 5}\end{array}$ & P value \\
\hline \multirow[t]{3}{*}{1.} & Gender (\%) & & & \multirow{3}{*}{0.39} \\
\hline & Male & $12(48)$ & $16(64)$ & \\
\hline & Female & $13(52)$ & $9(36)$ & \\
\hline 2. & Weight in grams, mean \pm SD & $2721.2 \pm 294.22$ & $2778.2 \pm 310.33$ & 0.51 \\
\hline 3. & Time of starting therapy in minuets, mean \pm SD & $125.32 \pm 70.79$ & $150.08 \pm 95.58$ & 0.30 \\
\hline 4. & Gestation age in weeks, mean \pm SD & $40.08 \pm 1.35$ & $39.92 \pm 1.68$ & 0.71 \\
\hline \multirow[t]{3}{*}{5.} & Mode of delivery, n (\%) & & & \multirow{3}{*}{1.00} \\
\hline & Vaginal & $12(48)$ & $13(52)$ & \\
\hline & Caesarean & $13(52)$ & $12(48)$ & \\
\hline 6. & Meconium stained amniotic fluid, n (\%) & $16(64)$ & $13(52)$ & 0.57 \\
\hline 7. & 5 minute apgar score, mean \pm SD & $4.08 \pm 1.12$ & $4.04 \pm 1.24$ & 0.90 \\
\hline 8. & Arterial blood gas $\mathrm{pH}$ values, mean $\pm \mathrm{SD}$ & $7.16 \pm 0.15$ & $7.18 \pm 0.17$ & 0.62 \\
\hline 9. & Arterial blood gas base excess values, mean \pm SD & $17.05 \pm 4.51$ & $17.06 \pm 5.20$ & 0.99 \\
\hline \multirow[t]{3}{*}{10} & Encephalopathy, n (\%) & & & \multirow{3}{*}{1} \\
\hline & Moderate & $17(68)$ & $16(64)$ & \\
\hline & Severe & $8(32)$ & $9(36)$ & \\
\hline \multirow[t]{4}{*}{11} & Serum magnesium level(Meq/L) & & & \\
\hline & Baseline & $1.49 \pm 0.34$ & & 0.12 \\
\hline & 24 hour & $2.87 \pm 0.58$ & & 0.03 \\
\hline & 72 hour & $2.91 \pm 0.74$ & & 0.01 \\
\hline
\end{tabular}

Table2: Assessment of outcome in moderate and severe grade HIE.

\begin{tabular}{|c|c|c|c|c|c|c|c|}
\hline \multirow{2}{*}{$\begin{array}{l}\text { S. } \\
\text { No. }\end{array}$} & \multirow[t]{2}{*}{ Characterestics } & \multicolumn{3}{|c|}{ Moderate HIE(N=34) } & \multicolumn{3}{|c|}{ Severe HIE(N=16) } \\
\hline & & Treated $(\mathrm{N}=17)$ & Plecebo(N=17) & $\begin{array}{c}\mathbf{P} \\
\text { velue }\end{array}$ & Treated(N=8) & $\begin{array}{c}\text { Plecebo } \\
(\mathbf{N}=8)\end{array}$ & $\begin{array}{c}\mathbf{P} \\
\text { velue }\end{array}$ \\
\hline 1 & $\begin{array}{l}\text { Control of seizures, } \\
\text { mean } \pm \text { SD (hours) }\end{array}$ & $13.67 \pm 1.67$ & $15.92 \pm 2.68$ & 0.04 & $18.38 \pm 2.26$ & $20.44 \pm 2.79$ & 0.12 \\
\hline 2 & $\begin{array}{l}\text { Appearance } \\
\text { normal cry, } \\
\pm \text { SD (days) }\end{array}$ & $10.8 \pm 1.15$ & $12.09 \pm 1.37$ & 0.02 & $16.33 \pm 0.58$ & $17.5 \pm 0.70$ & 0.13 \\
\hline 3 & $\begin{array}{l}\text { Appearance of } \\
\text { activity, mean } \pm \mathrm{SD} \\
\text { (days) }\end{array}$ & $12.2 \pm 1.01$ & $13.45 \pm 1.63$ & 0.02 & $18.33 \pm 1.52$ & $21 \pm 1.41$ & 0.14 \\
\hline 4 & $\begin{array}{l}\text { Acceptance of full } \\
\text { oral feed by sucking } \\
\text { mean } \pm \text { SD (days) }\end{array}$ & $13.46 \pm 1.19$ & $14.72 \pm 1.73$ & 0.04 & $17.67 \pm 1.52$ & $21 \pm 1.41$ & 0.09 \\
\hline 5 & $\begin{array}{lll}\text { Mean } & \text { duration } & \text { of } \\
\text { stay, } & \text { mean } & \pm S D \\
\text { (days) } & & \end{array}$ & $15.05 \pm 2.19$ & $16.63 \pm 2.16$ & 0.03 & $22.4 \pm 1.38$ & $24.3 \pm 1.26$ & 0.12 \\
\hline
\end{tabular}


Effectiveness of Magnesium Sulphatein Term Neonate with Perinatal Asphyxia: A Study in Faridpurmedical College Hospital, Faridpur, Bangladesh

\begin{tabular}{|l|l|l|l|l|l|l|l|}
\hline 6 & $\begin{array}{l}\text { Abnormal cranial } \\
\text { Sonography at day } \\
14(\%)\end{array}$ & $4(23.52)$ & $7(43.75)$ & 0.28 & $4(50)$ & $4(50)$ & 1.0 \\
\hline 7 & $\begin{array}{l}\text { Abnormal EEG at5(29.41) } \\
\text { day } 14(\%)\end{array}$ & $9(25.25)$ & 0.17 & $4(50)$ & $4(50)$ & 1.0 \\
\hline 8 & Mortality, n (\%) & $1(5.88)$ & 16.25 & 1.0 & $4(50)$ & $5(55.5)$ & 1.01 \\
\hline
\end{tabular}

4. DISCUSSION

Perinatal asphyxia is a major cause of morbidity and mortality in neonatal age group. It is also a leading cause of long term neurological sequel. Severity of PA depends on extant of insult, the metabolic imbalance during re oxygenation phase and the developmental state of affected organ [1]. Despite significant advancement in understanding of pathophysiologic mechanism, therapeutic interventions are still under initial development [1, 9]. Glutamate induced excitotoxicity, mediated by NMDA receptor opening is leading cause of perinatal asphyxia. Magnesium, being naturally occurring NMDA receptor antagonist is claimed to protect developmental brain byPA [7]. This also have neuroproctive proreties as well as capacity to down regulate pro inflammatory pathways [10]. Magnesium, in recommended dose do not increase any side effect profile in in these patients [11]. In present study we evaluated effectiveness of magnesium sulphate infusion in moderate and severe HIE. In neonates suffering from moderate PA, neurological improvement in terms of appearance of normal cry, appearance of normal activity, mean duration acceptance of full oral feed and duration of hospital stay was significantly better in treatment then placebo group. Similar results were also noted in other studies [12, 13]. Neonates suffering from severe PA did not show statistically significant neurological improvement when compared to placebo, which is similar to results of other studies [14, 2]. Reason for this poor response in patient with severe PA may be due to adverse pre natal and perinatal factors along with poor neurological status at birth. Time of infusion of magnesium sulphate is an important predictor of response as early intervention is essential in prevention of secondry phase of injury. Mean time of infusion of Magnisium sulphate in our patients is more as compared to other studies $[11,12,15]$ Improvement in investigative profile i.e. cranial ultrasonography and Electroencephalography did not showed significant improvement at 14 days in both moderate and severe group. Study Significant improvement in investigative profile was not recorded in other studies also [16]. Although significant improvement in short term parameters were witnessed in present study mortality benefits are not statistically proven similar results are found in other studies[12].This shows that magnesium therapy failed to prevent initial mortality due to asphyxia but beneficial in secondary insult.

\section{CONCLUSION}

Finally, it can be inferred from this study that postnatal magnesium sulfate infusion is safe in asphyxiated neonates and likely to improve the short term neurological outcome in moderate grade encephalopathy. However, more studies with larger sample sizes, preferably multicenter trials, are needed to confirm the results.

\section{REFERENCES}

[1] Morles P, Bustamante D, Marchant EP. Pathosyology of perinatal asphyxia: can we predict and improve individual outcome? EPMA Journal. 2011; 2:211-230.

[2] Anabrees J. Magnisium sulphate for newborn with HIE; Synopsis of evidence from asystemic review. J Clin Neonatol. 2013; 2(3):114-116.

[3] Paul VK. Neonatal morbidity: report of the National Neonataland Perinatal Database. Indian Pediatr. 1999; 36(2):167-169.

[4] Lawn JE, Cousens S, Stat DM. Four million neonatal deaths: When? Where? Why? The Lancet. 2005; 365: 891-900.

[5] Paneth N. The causes of cerebral palsy: recent evidence. Clin Invest Med. 1993; 16(2):95-102.

[6] Lorek A, Takei Y, Cady EB. Delayed (Secondary) cerebral energy failure after acute hypoxia- ischemia in the newborn piglet: Continuous 48- hour studies by phosphorus magnetic resonance spectroscopy. Pediatr Res.1994; 36(6):699-706.

[7] Prakash R. Effect of postnatal magnesium therapy in neonatal seizures in infant with moderate to severe hypoxic ischemic encephalopathy. A post hoc subgroup analysis. Int J Contemp Pediatric. 2016; 3(4): 1425-1429.

[8] Sarnet HB, Sarnet MS. Neonatal encephalopathy following fetal distress. A clinical and electroencephalographic study. Arch Neurol. 1976; 33: 696-705.

[9] Fan X, Van BF. Pharmacological neuroprotaction after perinatal asphyxia. J Matern Fetal Neonatal Med.2010; suppl 3:1719. 
Effectiveness of Magnesium Sulphatein Term Neonate with Perinatal Asphyxia: A Study in Faridpurmedical College Hospital, Faridpur, Bangladesh

[10] Lingram I, Robertson JN. Magnesium as a neuroprotactive agent: A review of its use in fetus, Term infant with neonatl encephalopathy and the Adult Stroke Patient. Dev Neurosci. 2018; 40: 1-12.

[11] Gathwala G, Khera A, Singh J, Balhara B. Magnesium for neuroprotection in birth asphyxia. J Pediatr Neurosci. 2010; 5:102-104.

[12] Bhat MA, Charoo BA, Bhat JI, Ahmad SM, Ali SW, Mufti MU. Magnesium sulfate in severe perinatal asphyxia: A randomized, placebocontrolled trial. Pediatrics. 2009; 123:e764-9.

[13] Savitha MR, Rajprakash. Beneficial effect of intravenous magnesium sulphate in perinatal asphyxia. Int J Contemp Peadiatric. 2016; 3(1):150- 152 .

[14] Sreenivasa B, Lokeshwari K, Joseph N. Role of magnesium sulphate in management and prevention of short term complication of birth asphyxia. Sri Lanka J Child Health. 2017; 46(2):148-151.

[15] Ichiba H, Tamai H, Negishi H, UedaT, Kim TJ, Sumida Y. Randomized controlled trial of magnesium sulfate infusion for severe birth asphyxia. Pediatr Int. 2002; 44(5):505-9.

[16] Tagin M, Shah PS, Lee KS. Magnesium for newborns with hypoxic ischemic encephalopathy: A systemic review and metaanalysis. J Perinatol.2013; 33: 663-669.

Citation: Md. Mahmuder Rahman Firoz, Effectiveness of Magnesium Sulphatein Term Neonate with Perinatal Asphyxia: A Study in Faridpurmedical College Hospital, Faridpur, Bangladesh. ARC Journal of Pediatrics.2021; 7(1) 6-10. Doi:doi.org/10.20431/2455-5711.0701002.

Copyright: (C) 2021 Authors. This is an open-access article distributed under the terms of the Creative Commons Attribution License, which permits unrestricted use, distribution, and reproduction in any medium, provided the original author and source are credited. 